\title{
Corrigendum
}

\section{Longitudinal growth of body weight and crown heel length in Punjabi infants : population comparison}

\author{
A.K. Bhalla, U. Kumar and S. Kaul. Indian J Pediatr 1987; 54 : 703-710
}

Editor's note: Due to an oversight, the following part of the text of the above article was deleted. Please replace page 707 with the enclosed leaflet incorporating pages 707 and $707 \mathrm{~A}$. The error is regretted.
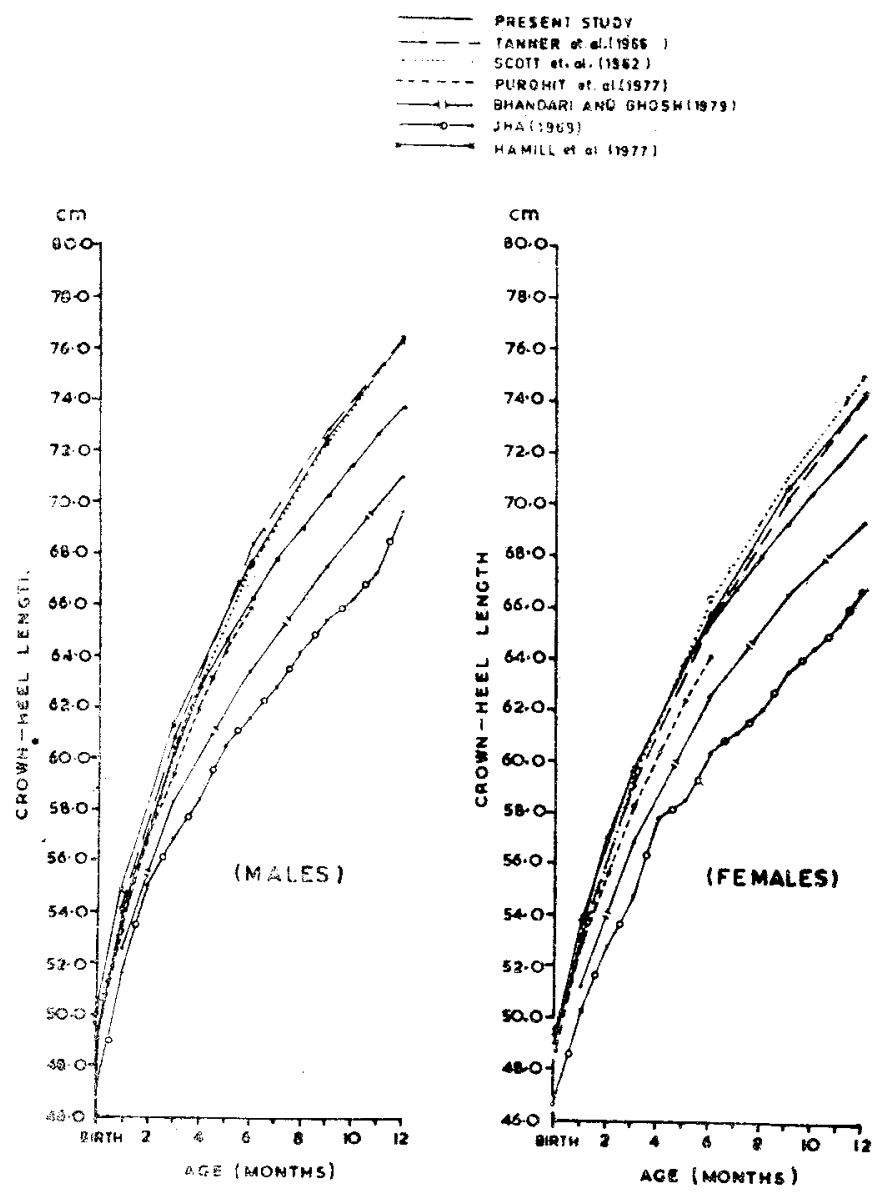

Fig. 2. Comparison of crown-heel length of male and female infants in various populations.

six months of age, as they all move parallel to each other. This pattern-wise similarity may be related to the protective effects of breast feeding which was continued in every child upto the age of 5-6 months. After six months of age growth curves for Punjabi infants diverge with flattening in comparison to their Western counterparts This also conforms to the findings of Raghavan ${ }^{12}$ who noticed that Indian infants grow parellel with American infants during the first six months of life after which there is a decreased rate of growth which continues during early childhood. However, when curves for infants from other parts of India are compared with those of Punjabi origin, we find a similar situation in which Indian 
infants studies at other places, generally, do not grow as well as their Punjabi counterparts, the differences being particularly noticeable in the second half of the first year.

A similar situation obtains when comparison with regard to crown-heel length are made (Fig. 2).

Habicht et al ${ }^{13}$ argued on the basis of review that children from various, ethnic groups, different socio-economic strata and geographic areas grow uniformly in length and weight during the first 3-6 months of life. After six months of life, the lengths and weights from developing countries lag behind the children from developed countries. The dampening of growth in body weight and length after 6 months in developing countries is related to the age of weaning and substitution of high starch and low protein foods, 14 insufficient lactation, ${ }^{13-16}$ delayed introduction of supplementary solid foods, ignorance on the part of mother and infection. ${ }^{17-20}$ Similar situation was encountered in the present study. It may however Be pointed out that growth dampening after six months was greater in other studies published from India ${ }^{6,21-22}$ than amongst Punjabi infants. This could be related to better economic and living conditions of Punjabis. In addition to nutritional inadequacy; illness and other environmental factors may also contribute to growth dampening. ${ }^{23}$

Information on incremental data on same number at monthly intervals is scant. The sizeable variability in the values in other studies can be partly attributed to the differences in age at which assessment is made, especially in situations where acceptable time tolerance limits are not adhered to. A comparison of velocity curves based on incremental data thus becomes difficult. In contrast, the present study has the advantage of adhering to the tolerance limits prescribed (Table). The variations are therefore 